\title{
Evaluation of Biodegradable Fixation System for Mandibular Angulus Fracture by Using Finite Element Method
}

\author{
M. Ay ${ }^{a}$, S. Hartomacioglu ${ }^{b, *}$, B. Bakircioglu ${ }^{c}$, H.E. Yuzbasioglu ${ }^{d}$ And T. Kubat ${ }^{b}$ \\ ${ }^{a}$ Department of Mechanical Engineering, Marmara University, 34722 Istanbul, Turkey \\ ${ }^{b}$ Department of Mechanical Education, Marmara University, 34722, Istanbul, Turkey \\ ${ }^{c}$ Department of Mechatronic, Selcuk University, 42600 Konya, Turkey \\ ${ }^{d}$ Department of Prosthodontics, Istanbul Medipol University, 34083, Istanbul, Turkey
}

\begin{abstract}
To date many fixation techniques of mandibular angle fractures have been introduced. There exist much research on the stability of plate and screws systems used in Champy technique in fixation of mandibular fractures. However the need of a second surgery for the removal of these plates and screws, and well known disadvantages of metallic fixations have led to the development of resorbable materials. It is thought that in order to achieve a safe and effective post-operative stability, the use of resorbable plates and screws is preferred for fixation. In this study, fixation evaluation of biodegradable plates which have been commonly used in recent years, was investigated using finite element method. 3D model required to perform the finite element analysis was obtained from CT scanning images using reverse engineering methods and material properties of mandible were obtained by Hounsfield Unit method. Biodegradable fixation systems were applied to this model and FEA was performed. It is concluded that biodegradable plate screw system used in the treatment of mandibular angle fractures shows a sufficient stability under masticatory forces.
\end{abstract}

DOI: 10.12693/APhysPolA.129.883

PACS/topics: 02.70.Dh-

\section{Introduction}

The mandibular angle is a common site for fractures. Fractures with displacements are often treated by open reduction and internal fixation using miniplates. Finite element analysis (FEA) is a computational technique originally developed by engineers to model the mechanical behavior of structures such as buildings, aircrafts, and engine parts. FEA is a numerical approach that addresses the complexity of the modeling by deriving an approximation to the solution. FEA has been used previously to evaluate the treatment of facial fractures [1-5]. Especially, O. Atali et al. reported strong correlation between FEA and experiments [2]. The aim of this study was the biomechanical validation of three-dimensional finite element analysis (FEA) for a resorbable fixation system (RFS).

\section{Materials and methods}

\subsection{Bio-CAD modeling}

In this study, according to the procedure previously reported by Sun et al., an image based bio-CAD modeling process was utilized [6], which involves following three major steps: (1) noninvasive image acquisition, (2) imaging process and three dimensional reconstructions (3DR) to form voxel-based volumetric image representation, and (3) construction of CAD-based model.

*corresponding author; e-mail: selimh@marmara.edu.tr
Furthermore, the obtained bio-CAD model was fabricated using rapid prototyping technology. An overall procedure of the image-based Bio-CAD modeling is illustrated in Fig. 1.

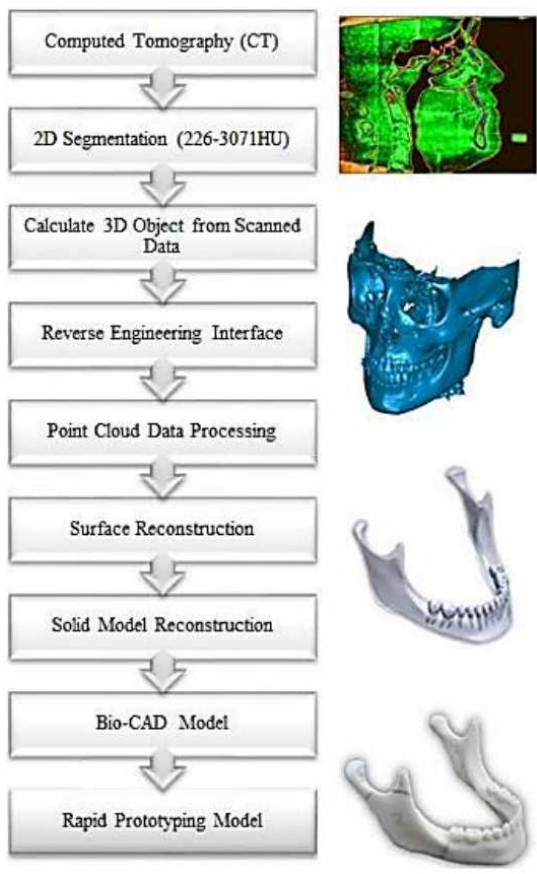

Fig. 1. Definition of processes for obtaining the BioCAD model from the CT data [6]. 


\subsection{Material model}

The material properties of the mandible were obtained using Hounsfield units (HU) method. The segmentation of mandible is shown in Fig. 2.

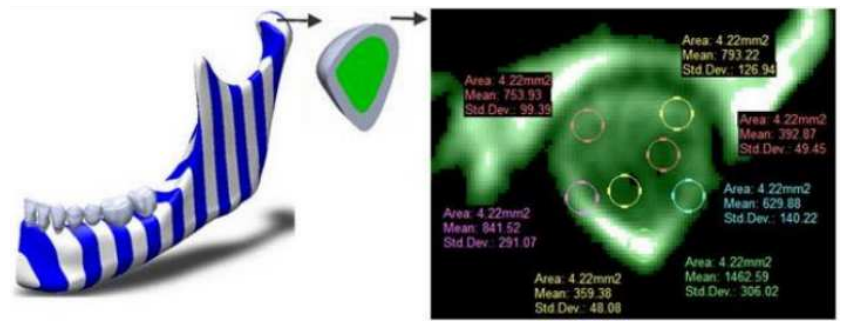

Fig. 2. The segmentation of mandible structure was divided into layers [6].

The Young modulus of cortical and cancellous bone exhibited different values. The average Young Modulus of cortical bone was $30100.88 \mathrm{MPa}$, whereas that of the cancellous bone was $685.42 \mathrm{MPa}$. Regarding the bio-Cad modeling processes and material models, more information can be found in Ref. [4].

\subsection{Biodegradable fixation system}

In this study, the resorbable fixation system consisted of $2.5 \mathrm{~mm}$ profile four-hole straight miniplates and $8 \mathrm{~mm}$ long screws, purchased from Inion (Inion CPS Biodegradable Fixation System: Inion Oy, Tampere, Finland). The resorbable plate was made by using amorphous poly-L-lactide (PLLA), poly-D, L-lactide (PDLLA), and trimethylene carbonate (TMC) copolymers. The RF system applied on the mandibular is shown in Fig. 3.
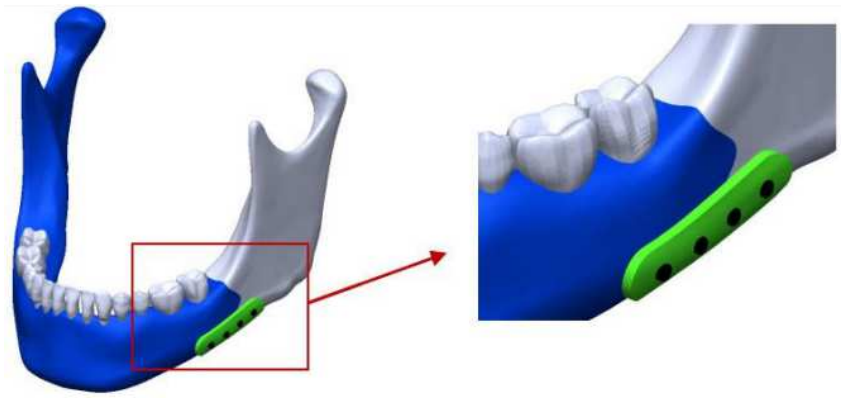

Fig. 3. Application of the RF system on the mandibular.

\subsection{Finite element analysis (FEA)}

Finite element analysis was performed using the Ansys 13 software. The solid finite element models were produced based on tetrahedral elements with 10 nodes. In the mesh generation process, model was divided into 1433722 tetrahedral (10-node) elements and 2210253 nodes, as shown in Fig. 4. All materials in this model were considered as isotropic, homogenous, and linearly elastic.

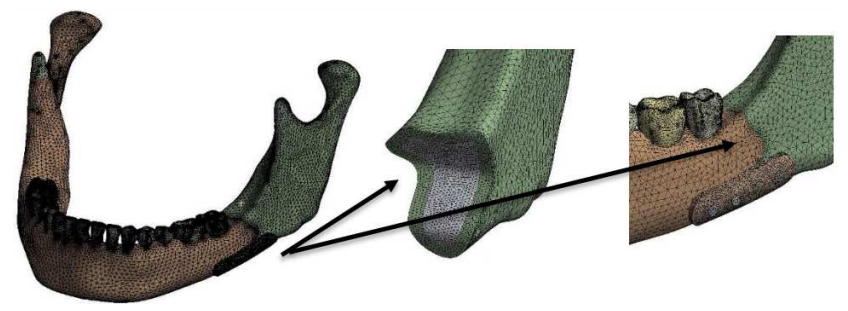

Fig. 4. Mesh generation process.

After the mandible was fixed (fixed support) at the muscle regions, the chewing forces of 0:50:250 N were applied at two different regions. The boundary conditions and loads are shown in Fig. 5.
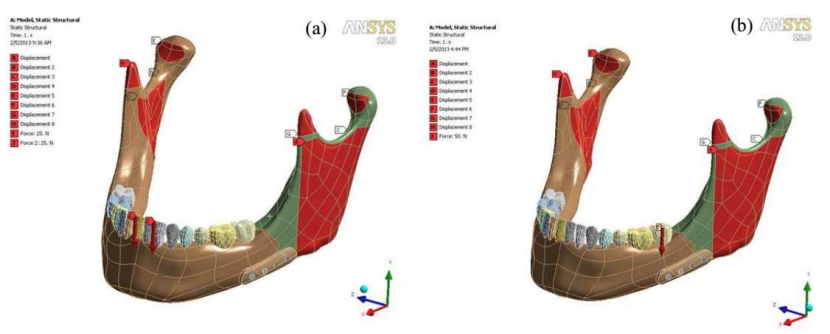

Fig. 5. Boundary conditions and loads for solution 1 (a), and solution 2 (b).

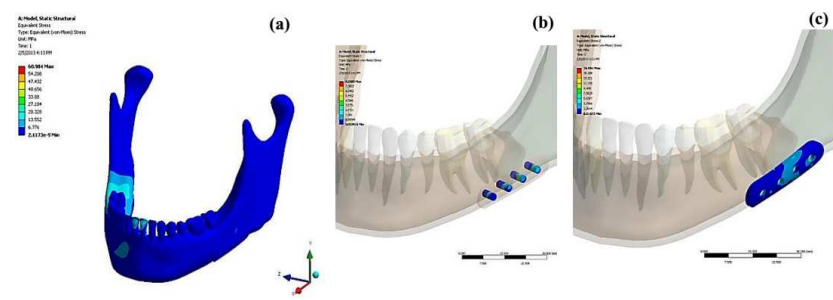

Fig. 6. Von-Mises stress distribution on Mandibular (a), screws (b), and plate (c).

A linear static solution was generated for each finite element model. This analysis assumes linear elastic material behavior. After solving each model, the VonMises stresses were recorded for each configurations of mandible, plate and screws. Regarding the above solution an example is shown in Fig. 6. The strength value of the resorbable fixation system was obtained from the supplier. The plate strength is $28 \mathrm{MPa}$, the screw strength is $38.2 \mathrm{MPa}$.

\section{Results and discussion}

In the case of maximum force of $250 \mathrm{~N}$ for solution 1 , the Von-Mises stress was calculated as 22.3 MPa for plate and 20.2 MPa for screws. In the case of maximum force of $150 \mathrm{~N}$ for solution 2, the Von-Mises stress was calculated as $30.74 \mathrm{MPa}$ for plate and 23.52 $\mathrm{MPa}$ for screws. It was found that the applied resorbable fixation system can withstand the chewing forces and the resorbable fixation system can be used in the mandibular angulus 
fractures. In the further studies, the experimental examination of resorbable fixation system will be performed and the results will be compared to the results of the finite element analysis (FEA).

\section{Acknowledgments}

The presented research was partially supported by Marmara University Research Grant. Project Number FEN-C-YLP-130612-0226

\section{References}

[1] P. Aquilina, U. Chamoli, W.C.H. Parr, P.D. Clausen, Brit. J. Oral Max. Surg. 51, 326 (2013).
[2] O. Atali, A. Varol, S. Basa, C. Ergun, S. Hartomacioglu, Brit. J. Oral Max. Surg. 43, 32 (2014).

[3] K.U. Feller, M. Schneider, M. Hlawitschka, G. Pfeifer, G. Lauer, J. Cranio-Maxill. Surg. 31, 290 (2003).

[4] D. Vollmer, U. Meyer, U. Joos, A. Vegh, J. Piffko, J. Cranio-Maxill. Surg. 28, 91 (2000).

[5] T.P. Bezerra, F.I. Silvia Junior, H.C. Scarparo, F.W.G. Costa, E.C. Studart-Soares, Int. J. Oral Max. Surg. 42, 474 (2013).

[6] M. Ay, T. Kubat, C. Delilbası, B. Ekici, H.E. Yuzbasioglu, S. Hartomacioglu, Usak Univ. J. Mater. Sci. 2, 135 (2013) 